\title{
Clopidogrel-Associated Thrombotic Thrombocytopenic Purpura following Endovascular Treatment of Spontaneous Carotid Artery Dissection
}

\author{
Jerry A. Rubano ${ }^{1} \quad$ Kwan Chen $^{2} \quad$ Brianne Sullivan $^{2}$ James A. Vosswinkel ${ }^{1}$ Randeep S. Jawa ${ }^{1}$ \\ ${ }^{1}$ Division of Trauma, Department of Surgery, Stony Brook University \\ School of Medicine, Stony Brook, New York, United States \\ 2 Stony Brook University School of Medicine, Stony Brook, New York, \\ United States

\begin{abstract}
Address for correspondence Randeep S. Jawa, MD, Division of Trauma, Department of Surgery, Stony Brook University School of Medicine, HSC Level 18, Room 040, Stony Brook, NY 11794-8191,
\end{abstract} \\ United States (e-mail: randeep.jawa@stonybrookmedicine.edu).
}

J Neurol Surg Rep 2015;76:e287-e290.

\begin{abstract}
Keywords

- clopidogrel

- TTP

- carotid

- stent

- thrombocytopenia

Thrombotic thrombocytopenic purpura (TTP) is a life-threatening multisystem disease secondary to platelet aggregation. We present a patient who developed profound thrombocytopenia and anemia 8 days following initiation of therapy with clopidogrel after stent placement for carotid artery dissection. She did not have a disintegrin and metalloproteinase with thrombospondin domain 13 (ADAMTS 13) deficiency. Management included steroids and therapeutic plasma exchange. Clopidogrel has rarely been associated with TTP. Unlike other causes of acquired TTP, the diagnosis of early clopidogrel-associated TTP is largely clinical given the infrequent reduction in ADAMTS 13 activity.
\end{abstract}

\section{Introduction}

Thrombotic thrombocytopenic purpura (TTP) is a rare multisystem disease, characterized by thrombocytopenia, microangiopathic hemolytic anemia, neurologic abnormalities, renal abnormalities, and fever. ${ }^{1-4}$ However, only thrombocytopenia and microangiopathic hemolytic anemia are required for diagnosis. ${ }^{3}$ Only $35 \%$ of patients have neurologic changes; these are subtle (i.e., headaches and confusion) and can easily be missed in neurosurgical patients with altered baseline levels of consciousness. ${ }^{2,3}$ Generally, noncongenital TTP is secondary to autoantibody mediated reduction in activity of a disintegrin and metalloproteinase with thrombospondin domain 13 (ADAMTS 13), a metalloproteinase that degrades von Willebrand factor (vWF). ${ }^{3,5}$ Reduced vWF proteolysis results in platelet aggregation with consequent microvascular thrombosis, thrombocytopenia, and hemolytic anemia. ${ }^{6}$ Although there have been case series of clopidogrel-associated TTP in the cardiac literature, there has been little discussion in the neurointerventional literature. We discuss a patient who likely developed TTP following clopidogrel administration after carotid artery stenting, along with its unique features.

\section{Case Report}

A middle-aged woman with untreated hypertension presented with altered mental status following an upper respiratory prodrome. She subsequently seized and became obtunded (Glasgow Coma Score 4T). Computed tomography and magnetic resonance imaging of the head and neck demonstrated multiple acute bihemispheric cerebral infarcts and bilateral internal carotid artery (ICA) dissection. Rheumatologic work-up for vasculitis was negative. Cerebral angiography demonstrated left ICA occlusion just distal to carotid bifurcation and a high-grade dissection of the entire extracranial right ICA. The right ICA dissection was managed with stenting (Carotid Wallstent Monorail Endoprosthesis, Boston Scientific, Marlborough, Massachusetts, United States) and Pipeline Embolization Device (Covidien-ev3, Plymouth, received

June 25, 2015

accepted

August 19, 2015

published online

October 25, 2015
DOI http://dx.doi.org/

10.1055/s-0035-1566127. ISSN 2193-6358.
@ 2015 Georg Thieme Verlag KG
Stuttgart · New York

License terms

(®) $\Theta \circledast$ 
Minessota, United States) placement from the cavernous to the distal cervical right ICA. Intraoperatively, the patient received heparin and abciximab. Postoperatively (hospital day [HD] 2), the patient was started on clopidogrel and aspirin (-Table 1). On HD 3, a bifrontal craniectomy was performed for cerebral edema.

Clopidogrel was held on days 4 and 5 because of the craniectomy. On HD 6 the clopidogrel response time (P2Y12 reaction units [PRU]) was nontherapeutic at 385; hence she was reloaded. Subsequent clopidogrel dosing was based on daily PRU measurements. On HD 9, her PRU decreased to 178 (therapeutic range $<194$ ) so she was maintained on $75 \mathrm{mg}$ clopidogrel daily. Clopidogrel was stopped after administration on HD 10 because of new profound thrombocytopenia with a platelet count of $46,000 / \mu \mathrm{L}$ with subsequent nadir to $3,000 / \mu \mathrm{L}$ (-Fig. 1). Petechial rash was noted on both arms. Four platelet pheresis units were transfused that day, with an increase of platelets to $15 \mathrm{k} / \mu \mathrm{L}$. Hemoglobin decreased to $6.3 \mathrm{~g} /$ $\mathrm{dl}$ (from $8.3 \mathrm{~g} / \mathrm{dL}$ on HD 9). Hence she was transfused 3 units of packed red blood cells.

Hematologic work-up demonstrated occasional schistocytes. Mildly increased lactate dehydrogenase, alanine transferase, and aspartate aminotransferase levels were noted. Haptoglobin and D-dimer levels were elevated. Total and indirect bilirubin, international normalized ratio, partial thromboplastin time, and fibrinogen levels were within normal limits. Serum creatinine level remained within normal limits. Her maximum temperature was $40.1^{\circ} \mathrm{C}$ on
HD 10. Her neurologic status was unchanged. Given subsequent concern for TTP, an ADAMTS13 level was sent; it was normal. Her Rose and Eldor score was 6, consistent with severe TTP. Intravenous methylprednisolone was started on HD 10 and gradually tapered off. Therapeutic plasma exchange (TPE) was begun on HD 11 and performed daily until HD 15. Her platelet counts increased from $47,000 / \mu \mathrm{L}$ after TPE on HD 11 to $242,000 / \mu \mathrm{L}$ on HD 15. Aspirin was resumed on HD 15. Her neurologic status remained unchanged.

\section{Discussion}

Following carotid and coronary artery stenting, thienopyridines and aspirin are prescribed to reduce the rate of stent thrombosis and consequent major complications. ${ }^{7-9}$ All three thienopyridines (ticlopidine, clopidogrel, and prasugrel) have been linked to TTP. Ticlopidine has the highest reported incidence of TTP at 1 case per 1,600 to 5,000 treated patients. ${ }^{6,10}$ Clopidogrel-mediated TTP is rare, with 11 cases reported among 3 million patients between 1998 and 2001 and 197 reported cases by 2011.,10 As noted in our patient, clopidogrel-associated TTP generally occurs within 2 weeks of therapy. ${ }^{4}$ In early thienopyridine-associated TTP ( $<2$ weeks), the mechanism is not known but involves microvascular endothelial cell damage. ${ }^{6}$ The mechanism may be nonimmunologic because no antibodies to ADAMTS13 have been reported in clopidogrel-associated TTP compared with $100 \%$

Table 1 Hospitalization course

\begin{tabular}{|c|c|c|c|c|c|c|c|c|c|c|c|}
\hline HD & Notes & $\begin{array}{l}\text { Tmax, } \\
C\end{array}$ & $\begin{array}{l}\text { Aspirin } \\
\text { dose, } \\
\text { mg }\end{array}$ & $\begin{array}{l}\text { Clopidogrel } \\
\text { dose, mg }\end{array}$ & PRU & $\begin{array}{l}\mathrm{Hgb}, \\
\mathrm{g} / \mathrm{dL}\end{array}$ & $\begin{array}{l}\text { Plate- } \\
\text { lets, k/ } \\
\text { mL }\end{array}$ & $\begin{array}{l}\mathrm{Cr} \text {, peak, } \\
\mathrm{mg} / \mathrm{dL}\end{array}$ & $\begin{array}{l}\text { PRBCs } \\
\text { trans- } \\
\text { fused }\end{array}$ & $\begin{array}{l}\text { Platelet } \\
\text { pheresis } \\
\text { trans- } \\
\text { fused }\end{array}$ & TPE \\
\hline 1 & Admit & 38.2 & - & - & - & 13.6 & 221 & 0.6 & - & - & - \\
\hline 2 & RICA stent & 38.6 & 300 & 600 & - & 11.0 & 199 & .43 & - & - & - \\
\hline 3 & Craniectomy & 38.5 & 325 & 75 & - & 9.9 & 161 & 0.44 & - & 1 & - \\
\hline 4 & & 38.7 & - & - & - & 8.8 & 145 & 0.55 & - & - & - \\
\hline 5 & & 39 & 325 & - & - & 9.1 & 171 & 0.56 & - & - & - \\
\hline 6 & PEG, trach & 38.9 & 325 & 300 & 385 & 8.1 & 194 & 0.72 & - & - & - \\
\hline 7 & & 38.8 & 325 & 375 & 361 & 7.1 & 180 & 0.58 & - & - & - \\
\hline 8 & & 38.5 & 325 & 675 & 318 & 8.5 & 251 & 0.58 & - & - & - \\
\hline 9 & & 39.1 & 325 & 75 & 178 & 8.3 & 253 & 0.60 & - & - & - \\
\hline 10 & & 40.1 & 325 & 75 & - & $\begin{array}{l}7.4 \text { to } \\
6.3\end{array}$ & 46 to 3 & 0.78 & 1 & 4 & - \\
\hline 11 & & 38.8 & - & - & - & 9.7 & 47 & 0.67 & 2 & - & 1 \\
\hline 12 & & 38 & - & - & - & 9.6 & 67 & 0.52 & - & - & 1 \\
\hline 13 & & 38.2 & - & - & - & 10 & 142 & 0.55 & - & - & 1 \\
\hline 14 & & 38.4 & - & - & - & 9.1 & 170 & 0.52 & - & - & 1 \\
\hline 15 & & 37.9 & 325 & - & - & 9.5 & 242 & 0.49 & - & - & 1 \\
\hline
\end{tabular}

Abbreviations: $\mathrm{Cr}$, creatinine; HD, hospital day; Hgb, hemoglobin; PEG, percutaneous endoscopic gastrostomy; PRBCs, packed red blood cells; PRU, P2Y12 reaction units; RICA, right internal carotid artery; Tmax, maximal temperature; TPE, therapeutic plasma exchange; trach, tracheostomy. 


\section{Platelet and Hemoglobin Concentrations}

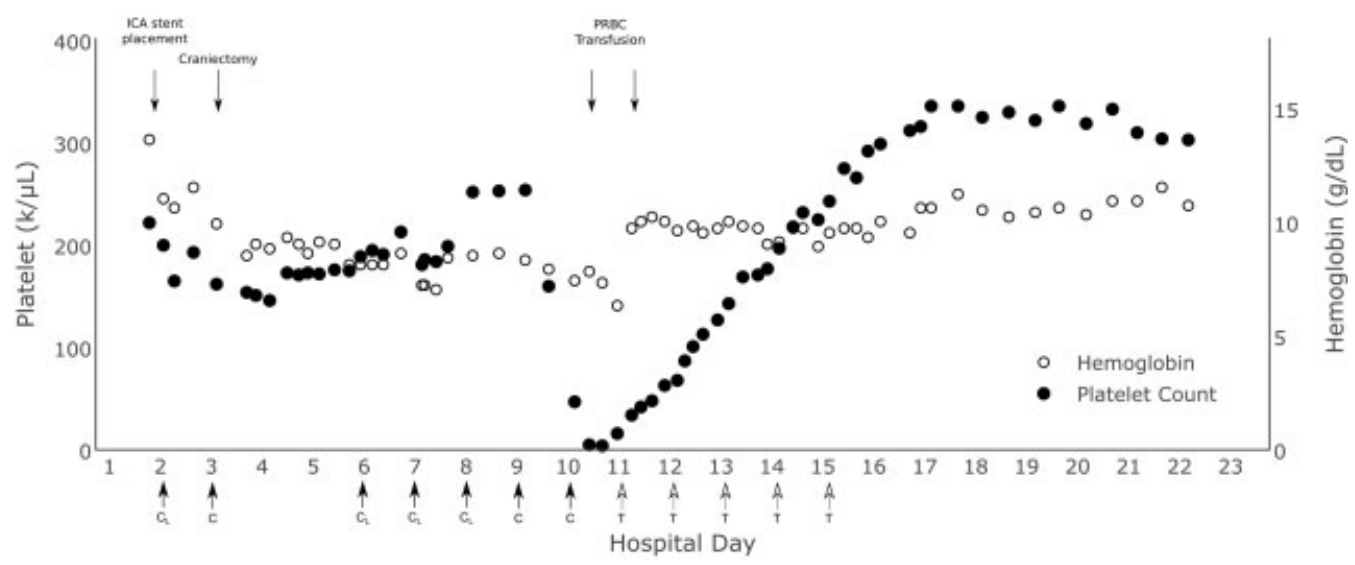

Fig. 1 C, clopidogrel maintenance dose, $C_{L}$, clopidogrel load; P, Plavix administered; T, therapeutic plasma exchange.

in 30 cases of ticlopidine-associated TTP. ${ }^{10}$ Notably, ADAMSTS13 activity deficiency has only been reported in a minority (0-22\%) of clopidogrel-associated TTP cases compared with severe deficiency in 80 to $100 \%$ of ticlopidineinduced TTP and virtually all cases of idiopathic TTP. 3,5,10,11 Hence clopidogrel-associated TTP appears to be primarily a clinical diagnosis. To this end, the Rose and Eldor scoring system, based on platelet count, hemoglobin, serum creatinine, and neurologic function, has been used to assess the likelihood of TTP; a score $\geq 4$ of 8 indicates a high probability of TTP. ${ }^{1,4}$

Given the highly thrombogenic nature of the Pipeline devices, as used in this case, antiplatelet therapy was guided by PRU. Because clopidogrel is a prodrug and patients are variably responsive, reloading may be performed. It has been shown to overcome platelet nonresponsiveness, with reduced rates of myocardial infarction, stent thrombosis, and cardiovascular death following cardiac stenting. ${ }^{12-14}$

Management recommendations for clopidogrel-associated TTP are based on case reports. Clopidogrel should be discontinued. The role of TPE is unclear. Unlike cases of thienopyridineassociated TTP occurring after 2 weeks of therapy, where TPE dramatically improves survival (84\% versus $38 \%$ ), in patients treated with clopidogrel for $<14$ days who had TTP $(n=26)$, survival was $70 \%$ with TPE and $66.7 \%$ without TPE. ${ }^{11}$ Additional recommendations that are not specific to early thienopyridineassociated TTP include (1) continue TPE for at least 2 days after platelet count $>150 \mathrm{k} / \mu \mathrm{L}$; (2) avoid platelet transfusion in the absence of life-threatening bleeding; (3) administer high-dose steroids and folic acid; (4) consider aspirin and prophylactic dose low-molecular-weight heparin when platelet count is $>50 \mathrm{k} / \mu \mathrm{L}$; (5) PRBC transfusion as needed; and (6) advise patients of possibility of relapse. ${ }^{2-4}$

\section{Conclusions}

Clopidogrel-associated TTP generally occurs within 2 weeks of the initial dose of clopidogrel. Because there is frequently no ADAMTS13 activity deficiency, diagnosis is primarily clinical, such as the Rose and Eldor score. Management is largely based on case reports. To our knowledge, this phenomenon has not been described in the neurocritical care literature. Given the frequency of neurointerventional endovascular procedures and the consequent need for dual antiplatelet therapy, this uncommon side effect must be recognized.

Financial Disclosure

Randeep S. Jawa received a Stony Brook University Department of Surgery Research Grant to evaluate vitamin D binding protein in mice.

\section{References}

1 Rose M, Rowe JM, Eldor A. The changing course of thrombotic thrombocytopenic purpura and modern therapy. Blood Rev 1993; $7(2): 94-103$

2 George J, Leung L, Timauer J. Diagnosis of thrombotic thrombocytopenic purpura-hemolytic uremic syndrome in adults. Available at: http://www.uptodate.com.proxy.library.stonybrook.edu/contents/diagnosis-of-thrombotic-thrombocytopenic-purpura-hemolytic-uremic-syndrome-in-adults?sour-

$\mathrm{ce}=$ search_result\&search $=\mathrm{ttp}+$ diagnosis\&selectedTitle $=1 \sim 150$. Accessed May 27, 2015

3 Scully M, Hunt BJ, Benjamin S, et al; British Committee for Standards in Haematology. Guidelines on the diagnosis and management of thrombotic thrombocytopenic purpura and other thrombotic microangiopathies. Br J Haematol 2012;158(3): 323-335

4 Bennett CL, Connors JM, Carwile JM, et al. Thrombotic thrombocytopenic purpura associated with clopidogrel. N Engl J Med 2000; 342(24):1773-1777

5 Verbij FC, Fijnheer R, Voorberg J, Sorvillo N. Acquired TTP: ADAMTS13 meets the immune system. Blood Rev 2014;28(6): 227-234

6 Zakarija A, Kwaan HC, Moake JL, et al. Ticlopidine- and clopidogrel-associated thrombotic thrombocytopenic purpura (TTP): review of clinical, laboratory, epidemiological, and pharmacovigilance findings (1989-2008). Kidney Int Suppl 2009; (112):S20-S24 
7 Ricotta JJ, Aburahma A, Ascher E, Eskandari M, Faries P, Lal BK; Society for Vascular Surgery. Updated Society for Vascular Surgery guidelines for management of extracranial carotid disease. J Vasc Surg 2011;54(3):e1-e31

8 Liapis CD, Bell PR, Mikhailidis D, et al; ESVS Guidelines Collaborators. ESVS guidelines. Invasive treatment for carotid stenosis: indications, techniques. Eur J Vasc Endovasc Surg 2009;37(4, Suppl):1-19

9 Bell B, Layland J, Poon K, Spaulding C, Walters D. Focused clinical review: periprocedural management of antiplatelet therapy in patients with coronary stents. Heart Lung Circ 2011;20(7):438-445

10 Jacob S, Dunn BL, Qureshi ZP, et al. Ticlopidine-, clopidogrel-, and prasugrel-associated thrombotic thrombocytopenic purpura: a 20-year review from the Southern Network on Adverse Reactions (SONAR). Semin Thromb Hemost 2012;38(8):845-853

11 Bennett CL, Kim B, Zakarija A, et al; SERF-TTP Research Group. Two mechanistic pathways for thienopyridine-associated thrombotic thrombocytopenic purpura: a report from the SERF-TTP Research
Group and the RADAR Project. J Am Coll Cardiol 2007;50(12): 1138-1143

12 Matetzky S, Fefer P, Shenkman B, Varon D, Savion N, Hod H. Effectiveness of reloading to overcome clopidogrel nonresponsiveness in patients with acute myocardial infarction. Am J Cardiol 2008;102(5):524-529

13 Tan LA, Keigher KM, Munich SA, Moftakhar R, Lopes DK. Thromboembolic complications with Pipeline Embolization Device placement: impact of procedure time, number of stents and pre-procedure P2Y12 reaction unit (PRU) value. J Neurointerv Surg 2015;7(3):217-221

14 Price MJ, Angiolillo DJ, Teirstein PS, et al. Platelet reactivity and cardiovascular outcomes after percutaneous coronary intervention: a time-dependent analysis of the Gauging Responsiveness with a VerifyNow P2Y12 assay: Impact on Thrombosis and Safety (GRAVITAS) trial. Circulation 2011; 124(10):1132-1137 